\title{
A EDUCAÇÃO DO CAMPO EM DISPUTA: RESISTÊNCIA VERSUS SUBALTERNIDADE AO CAPITAL*
}

\author{
Rodrigo Simáo Camacho ${ }^{1}$
}

\begin{abstract}
RESUMO: O objetivo deste artigo foi demonstrar as diferenças paradigmáticas existentes entre a Educaçáo do Campo construída a partir da tendência campesinista do Paradigma da Questão Agrária (PQA) e a proposta de Educação do Campo construída a partir do Paradigma do Capitalismo Agrário (PCA), tendo como recorte analítico a experiência do Programa Empreendedorismo do Jovem Rural (PEJR), financiado pelo Instituto Souza Cruz (ISC) e implementado pelo Centro de Desenvolvimento do Jovem Rural (CEDEJOR), no Centro-Sul do Paraná. Com esta análise pretendemos defender o Paradigma Originário da Educação do Campo. As metodologias utilizadas foram a análise da unidade político-pedagógica, a observação participante e as entrevistas com coordenadores, educandos, monitores e educadores.
\end{abstract}

Palavras-chave: Paradigmas. Disputas. Educação do Campo. Resistência. Programa de Empreendedorismo do Jovem Rural.

\section{RURAL EDUCATION IN DISPUTE: RESISTANCE VERSUS SUBALTERNITY TO CAPITAL}

ABSTRACT: The goal of this paper was to depict the paradigm differences between countryside education built up from the peasant trend of the Paradigmatic Agrarian Matter (PQA) and the offer of Countryside Education based on the Agrarian Capitalism Paradigm (PCA), focusing on the experience of the Rural Youth Entrepreneurship Program, established by Souza Cruz Institute (ISC) and implemented by Rural Youth Development Center (CEDEJOR) in center-south Paraná. From this analysis, the intention is to support the paradigm originating countryside education. Methodology used involved political-pedagogical analysis, participating observation, and interviews with coordinators, students, instructors, and educators.

Keywords: Paradigms. Disputes. Rural Education. Resistance. Rural Youth Entrepreneurship Program.

\footnotetext{
*A produção deste texto tem, parcialmente, origem na pesquisa de tese de doutorado intitulada Paradigmas em Disputa na Educação do Campo, defendida em 2014 no Programa de Pós-Graduaçấo em Geografia da Faculdade de Ciências e Tecnologia (FCT), da Universidade Estadual Paulista (UNESP) e financiada pela Fundação de Amparo à Pesquisa do Estado de São Paulo (FAPESP).

${ }^{1}$ Universidade Federal da Grande Dourados, Faculdade Intercultural Indígena - Dourados (MS), Brasil.

E-mail: rogeo@ymail.com
}

DOI: 10.1590/ES0101-73302017177792 


\section{L'ÉDUCATION RURALE EN DISPUTE: RESISTANCE VERSUS SUBORDINATION AU CAPITAL}

RESUME: L'objectif de cet article est de démontrer les différences paradigmatiques existantes entre l'Éducation Rurale construite à partir de la tendance paysanne du Paradigme de la Question Agraire (PQA), et la proposition de l'Éducation Rurale construite à partir du Paradigme du Capitalisme Agraire (PCA), en soulignant l'expérience du Programme Entrepreneurial de la Jeunesse Rurale (PEJR) financée par l'Institut Souza Cruz (ISC) et mis en œuvre par le Centre de Développement de Jeunesse Rurale (CEDEJOR) dans le Centre-Sud de l'État de Paraná. Sur la base de cette analyse, l'intention était de soutenir le Paradigme Originaire de l'Éducation Rurale. La méthodologie a compris l'analyse du Projet Politico-Pédagogique, l'observation participante et des entretiens avec coordinateurs, étudiants, moniteurs et éducateurs.

Mots-clés: Paradigmes. Disputes. Éducation Rurale. Résistance. Programme Entrepreneurial de la Jeunesse Rurale.

\section{Introdução}

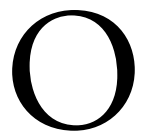

objetivo deste artigo foi demonstrar as diferenças dos aspectos teóricos, políticos e ideológicos existentes entre a Educação do Campo construída a partir da tendência campesinista do Paradigma da Questão Agrária (PQA) e a proposta de Educação do Campo construída a partir do Paradigma do Capitalismo Agrário (PCA), tendo como recorte analítico a experiência do Programa de Empreendedorismo do Jovem Rural (PEJR), que recebe apoio técnico, pedagógico e financeiro do Instituto Souza Cruz (ISC), e é implementado pelo Centro de Desenvolvimento do Jovem Rural (CEDEJOR), no Centro-Sul do Paraná. Com esta análise, pretendemos defender o que consideramos ser o Paradigma Originário da Educação do Campo (POEC) e afirmar a tese de que o território teórico da Educação do Campo está amparado na tendência campesinista do PQA.

Assim, nossa reflexão está calcada em torno de dois paradigmas: o PQA e o PCA. A tendência campesinista do PQA defende a tese da recriação camponesa, e entende que o desenvolvimento do capitalismo no campo se faz a partir de um movimento desigual e contraditório. No PCA, a tese principal é da metamorfose do campesinato em agricultor familiar a partir da integração do camponês ao mercado. Nossa tese central é a de que a Educação do Campo é um território imaterial, construído política-ideologicamente a partir da tendência campesinista do PQA.

Ao justificarmos de maneira teórico-político-ideológica a existência da Educação do Campo em dois paradigmas, partimos da premissa de que esse mo- 
delo de educação está em disputa, porque o campo está em disputa por modelos distintos de desenvolvimento territorial e de educação. A Educaçáo do Campo nasceu da luta dos movimentos camponeses, mas foi apropriada pelo Estado e pelas grandes empresas e seus institutos de responsabilidade social. Muitas das práticas intituladas dessa forma são reacionárias e rompem com o caráter revolucionário, essência da Educação do Campo, formando para subalternidade ao capital ao invés de para a resistência política, cultural e econômica.

Enquanto a Educação do Campo no PQA objetiva a formação para a resistência, inclusive formando militantes dos movimentos socioterritoriais, por outro lado aquela construída a partir do PCA, o PEJR, visa a formar empreendedores rurais na lógica da profissionalização dos camponeses para competir e se integrar ao mercado, de maneira subalterna ao capital.

Por isso, fizemos uma análise crítica da experiência do PEJR, que tem o objetivo de integrar segura e plenamente os jovens do campo no processo produtivo, apostando na sua metamorfose em agricultor familiar. O discurso principal é o de que o fortalecimento da capacidade empreendedora da juventude da agricultura familiar é algo capaz de promover o desenvolvimento territorial sustentável.

Como metodologia, fizemos a análise da Unidade Política e do Projeto Pedagógico do PEJR e dos documentos do ISC e do CEDEJOR. Entrevistamos os coordenadores do ISC, coordenadores e educadores do CEDEJOR, e os educandos-camponeses do PEJR. Para isso, entre os anos de 2011 e 2013 fizemos quatro trabalhos de campo no CEDEJOR, em Guamiranga, no centro-sul do Paraná, onde realizamos observaçáo-participante e entrevistas, e um trabalho de campo no ISC no Rio de Janeiro (RJ), onde realizamos entrevistas.

O texto está organizado em três partes. A primeira explica as diferenças paradigmáticas entre o PQA e o PCA na interpretação acerca da questão agrária. A segunda explica o que é a Educação do Campo em seu paradigma originário, ou seja, o PQA, e quais são seus pressupostos teórico-político-ideológicos. E a terceira parte visa a fazer uma crítica à concepção de Educação do Campo construída a partir do PCA, mostrando o trabalho documental e de campo na experiência pesquisada.

\section{Definindo as diferenças paradigmáticas: Paradigma da Questão Agrária versus Paradigma do Capitalismo Agrário}

Para entendermos o processo de construção e consolidação da Educação do Campo, é necessário discutirmos a questão agrária, ou seja, como se dão as relaçóes sociais no modo de produção capitalista. Para isso, vamos analisar a questão agrária a partir de um debate paradigmático. Existem duas vertentes de interpretação das relaçóes sociais no campo que engendram dois paradigmas ${ }^{1}$ distintos: PQA e PCA. 
Partimos da perspectiva de que o PQA é formado por autores que entendem que a questão agrária é um problema estrutural, logo, somente poderá ser resolvido com a luta contra o capitalismo, defendendo a necessidade de superaçáo desse sistema. Os elementos de análise principais presentes nesse paradigma são: a luta de classes, o conflito, as disputas e a superaçáo do capitalismo (FERNANDES, 2008; CAMACHO, 2014).

O fim ou a permanência camponesa no capitalismo é uma problemática discutida desde as obras seminais desse paradigma. A primeira concepção presente na obra que originou o PQA, A Questão Agrária, de Kautsky (1980), é a afirmação de que o desenvolvimento do capitalismo no campo tende a, necessariamente, expropriar o campesinato e proletarizá-lo, ou seja, ocorrerá uma inevitável destruição do campesinato (OLIVEIRA, 2004; FERNANDES, 2008). Todavia, existe outra vertente (e somos parte desta), que defende a existência da recriação camponesa. É o que estamos denominando de vertente campesinista do PQA. Esta entende que o desenvolvimento do capitalismo no campo se faz a partir de um movimento desigual e contraditório (OLIVEIRA, 2004). Isso significa que existe um processo de produção de capital por meio de relaçóes não capitalistas (MARTINS, 1981; OLIVEIRA, 2004). Por isso, o campesinato é uma classe social e um modo de vida heterogêneo e complexo, baseado no tripé interdependente terra-família-trabalho, inerente à contradição do modo de produção capitalista e não um resíduo social em vias de extinção. Ele se recria, assim, na contradição estrutural e por meio da compra, da luta pela terra e da sua resistência ao capital (SHANIN, 2008; OLIVEIRA, 2004; FERNANDES, 2008; MARQUES, 2008; ALMEIDA; PAULINO, 2010).

Podemos identificar a maneira particular com a qual o camponês se relaciona com a sociedade a partir da combinação de vários elementos, como um "modo de vida". O campesinato é marcado pela flexibilidade de adaptação com a finalidade de reproduzir, material e culturalmente, o seu modo de vida camponês. Este não é tipicamente capitalista, pois não tem como fundamento principal a acumulação - o princípio fundamental do campesinato é a reprodução material e cultural familiar, por meio da produção para subsistência e a venda do excedente dessa produção (SHANIN, 2008; OLIVEIRA, 1986; ALMEIDA; PAULINO, 2010).

Esse processo significa uma forma simples de produção/circulação das mercadorias, porque a transformação de bens em dinheiro ocorre com o objetivo apenas de adquirir outros produtos necessários à satisfação de necessidades. Assim, do ponto de vista econômico, a produção camponesa pode ser pensada como uma relação social não capitalista (OLIVEIRA, 1986; CAMACHO, 2014).

Uma diferença fundamental do campesinato com relação ao trabalhador assalariado diz respeito ao fato de que o operário, despossuído dos meios de produção, é obrigado a vender sua força de trabalho ao capital e, por isso, o proletário se situa no mundo por meio do seu trabalho. Mas "o camponês se situa no mundo através do seu produto, seu trabalho se oculta no seu produto" (MARTINS, 2002). 
É a única classe que contém os dois elementos que são fundamentais para a sua reprodução: os meios de produção e a força de trabalho (ALMEIDA; PAULINO, 2010). Por isso,

[e]ntendemos o campesinato como uma classe social e não apenas como um setor da economia, uma forma de organização da produção ou um modo de vida. Enquanto o campo brasileiro tiver a marca da extrema desigualdade social e a figura do latifúndio se mantiver no centro do poder político e econômico esteja ele associado ou não ao capital industrial e financeiro o campesinato permanece como conceito-chave para decifrar os processos sociais e políticos que ocorrem neste espaço e suas contradiçóes (MARQUES, 2008, p. 58, grifo nosso).

No entanto, existe uma interpretação divergente acerca da questão camponesa no capitalismo, a da metamorfose do campesinato em agricultor familiar. Os teóricos que defendem essa posição configuram o que denominamos de PCA, que tem como principal representante no Brasil o pesquisador Abramovay, e sua tese de doutorado, publicada em 1992, com o título Paradigmas do Capitalismo Agrário em Questão. Nesse trabalho, ao romper com o PQA, ou com o debate marxista da questáo agrária, o autor defende que os camponeses nem vão se proletarizar e nem se transformarão em capitalistas, como diziam os clássicos marxistas. Mas também não vão continuar existindo como camponeses, pois as relações camponesas são incompatíveis com as relaçóes de mercado capitalista. O que o autor defende é que esses sujeitos sofreram/sofrerão uma metamorfose a partir da sua integração plena ao capital, auxiliados pelas políticas públicas, e se tornaram/tornarão os agricultores mais eficientes de nossa época. Nesse caso, esses sujeitos, ex-camponeses, passaram a ser denominados de agricultores familiares, por serem profissionais, modernos, integrados etc. Criando, assim, uma dicotomia na qual o arcaico, ineficiente, miserável e condenado a desaparecer é o camponês; e o moderno, eficiente, próspero e compatível com o mercado é o agricultor profissional (CAMACHO, 2014).

A agricultura de base familiar moderna, de acordo com Abramovay (1992), se diferencia da agricultura camponesa pelas seguintes características: $a$ natureza empresarial, o dinamismo técnico, a capacidade de inovação, a integração plena ao mercado e a capacidade de responder a intervençáo do Estado. Nesse caso, a profissionalizaçáo e a inovação são requisitos que separaram a agricultura arcaica, camponesa, da moderna, familiar. O autor é enfático em afirmar que $a$ alta integração ao mercado, a incorporação de avanços técnicos e de políticas governamentais são caracteristicas que diferenciam a agricultura familiar da agricultura camponesa. Em suas palavras: "uma agricultura familiar, altamente integrada ao mercado, capaz de incorporar os principais avanços técnicos e de responder às políticas governamentais não pode ser nem de longe caracterizada como camponesa" (ABRAMOVAY, 1992, p. 22, grifo do autor). 
Entendemos que não é necessário criarmos um novo conceito para explicar as diferenciaçóes entre os camponeses. A perspectiva de que o camponês é o irracional e o agricultor familiar é o moderno e empreendedor é uma falsa dicotomia. Para o PQA, essa mesma realidade é interpretada pela existência de uma diferenciaçâo social entre os camponeses. Nessa perspectiva, trata-se, na verdade, de uma estratificação rural provocada pelo próprio movimento desigual do capital. Nesse movimento, o capital pode diferenciá-los, expropriá-los ou recriá-los. Como consequência desse processo, teremos camponeses viabilizados, remediados, empobrecidos e excluidos. Os camponeses empobrecidos têm resistido para permanecer no campo e os camponeses excluídos são os camponeses sem terra que estáo lutando para se territorializarem. Sendo assim, teríamos apenas estratificaçóes diferentes de camponeses e náo duas categorias distintas no interior de uma mesma classe (FERNANDES, 2009; CAMACHO, 2014).

De maneira geral, o PCA trabalha na perspectiva de integração do agricultor ao capital. Assim, subalternidade e expropriação são vistas como sendo resultado de uma suposta ineficácia do campesinato (FERNANDES, 2008). Entretanto, no PQA, essa integração é o sinônimo de subordinação da renda do campesinato ao capital e, consequentemente, subalternidade ao capital, no interior de um processo de produção de capital por meio de relações sociais não capitalistas (MARTINS, 1981; OLIVEIRA, 2004). Nesses processos, o camponês náo é expropriado, mas sua renda fica subordinada ao capital ao repassar o produto do seu trabalho para o capitalista (OLIVEIRA, 2004). Essa parte da renda camponesa, que é apropriada pelo capitalista, é utilizada por este para reprodução/acumulação de capital (MARTINS, 1981). Apesar de permitir que o campesinato continue se reproduzindo, essa condição faz com que o camponês se reproduza em uma situação precária, daí a necessidade de uma ruptura com o capital (ALMEIDA; PAULINO, 2010).

A resistência também é um conceito presente no PQA, na perspectiva do debate da permanência camponesa pela luta na/pela terra-território. Esses processos estão, assim, diretamente vinculados às abordagens de destruição e recriação do campesinato e seus territórios. Sendo assim, a resistência diz respeito a todo embate do campesinato frente às condiçóes impostas pelo capital, quer seja desterritorializando/proletarizando ou monopolizando o território camponês (CAMACHO, 2014). Por isso, a característica marcante que delimita o antagonismo dialético entre esses dois paradigmas é a afirmação da luta de classes - e do campesinato como parte inerente dessa luta — por parte do PQA; e a negação das classes sociais e a substituiçáo do conceito de campesinato pela sua metamorfose em agricultor familiar, por parte do PCA, ou seja, na metamorfose do camponês em agricultor familiar, ocorre a conversão daquilo que era um modo de vida em uma profissão (ABRAMOVAY, 1992).

Nesse sentido temos, de um lado, no PQA, a crítica ao modelo vigente principalmente aos impactos socioterritoriais causados pela expansão do agronegócio ${ }^{2}$ - 
e a perspectiva de superação desse modelo, apontando para a possibilidade e para a necessidade de construção de outro modelo, por meio da luta/disputa/conflitos territoriais entre classes e grupos sociais. E do outro lado, no PCA, temos a defesa à adaptaçáo/ integração que auxilie no processo de produção/reprodução/acumulação de capital. A Educação do Campo encontra-se no centro desse debate, que envolve opçóes teóricas, políticas e ideológicas presentes nas disputas em torno dos paradigmas acadêmicos, das políticas públicas e das disputas territoriais entre o agronegócio e o campesinato, envolvendo nesse processo: a universidade, o Estado e os movimentos sociais. Esses conflitos fazem parte de um mesmo conjunto estrutural de processos dinâmicos que envolvem a insuperável questão agrária no interior do modo de produção capitalista (FERNANDES, 2008; CAMACHO, 2014).

No Quadro 1, explicitamos as principais diferenças desses dois paradigmas em disputa na Educação do Campo.

\section{A Educação do Campo no Paradigma da Questão Agrária}

A criação de um projeto de Educação do Campo está relacionada com as experiências educativas alternativas que os movimentos socioterritoriais ${ }^{3}$ camponeses, principalmente o Movimento dos Trabalhadores Rurais Sem Terra (MST), vinham desenvolvendo em acampamentos e assentamentos. Elas foram sistematizadas nos seminários e encontros regionais e nacionais a partir da segunda metade da década de 1990. Com os esforços conjuntos de algumas entidades, formou-se, em 1998, a Articulação Nacional "Por uma Educação do Campo". Esse movimento foi criado para fazer frente à realidade de abandono por parte do Estado. Começaram a exigir políticas públicas de instituiçóes governamentais, bem como o financiamento para a investigação relacionada com questóes educacionais em comunidades rurais. O silêncio, o esquecimento, e até mesmo a falta de interesse em comunidades rurais em pesquisas sociais e educacionais é um ponto que estava se tornando preocupante. Por isso, o movimento foi criado para relatar esse silêncio e o esquecimento das instituições que estudam as questóes sociais e educacionais (ARROYO et al., 2004; ARROYO, 2004; CAMACHO, 2014).

A primeira conferência nacional, chamada "Por uma Educação Básica do Campo", ocorreu em Luziânia (GO), em 1998. As entidades que promoveram o evento foram: a Conferência Nacional dos Bispos do Brasil (CNBB); o MST; o Fundo das Naçôes Unidas para a Infância (UNICEF); a Organização das Nações Unidas para a Educação, a Ciência e a Cultura (UNESCO); a Universidade de Brasília (UnB); e o Grupo de Trabalho da Reforma Agrária (GTRA) (CAMACHO, 2014).

As razões que estão por trás da luta pela Educação do Campo no Brasil são fruto da realidade de exclusão dos habitantes do meio rural. A falta de acesso a um ensino que permita o desenvolvimento territorial das comunidades no campo 


\section{Quadro 1}

Síntese das diferenças paradigmáticas da Educação do Campo.

\begin{tabular}{|c|c|}
\hline Educaçáo do Campo no PQA ${ }^{10}$ & Educaçáo do Campo no $\mathrm{PCA}^{11}$ \\
\hline Inovação como resistência & Inovação como metamorfose \\
\hline $\begin{array}{l}\text { Protagonismo dos movimentos socioterritoriais } \\
\text { na implantaçáo de políticas públicas }\end{array}$ & $\begin{array}{l}\text { Protagonismo das ONGs com financiamento } \\
\text { de empresas }\end{array}$ \\
\hline $\begin{array}{l}\text { Resistência à territorialidade do capital } \\
\text { e à monopolização dos territórios }\end{array}$ & $\begin{array}{l}\text { Adaptação à territorialidade do capital e } \\
\text { aceitaçâo da monopolizaçáo }\end{array}$ \\
\hline Ruptura com o mercado & Adesão ao mercado \\
\hline A resistência como continuidade camponesa & $\begin{array}{l}\text { A resistência como } \\
\text { possibilidade de proletarização }\end{array}$ \\
\hline A integração como subalternidade & A integração como continuidade \\
\hline Questóes estruturais & Questóes conjunturais \\
\hline Paradigma Originário da Educação do Campo & Ressignificação da Educação do Campo \\
\hline $\begin{array}{l}\text { Movimentos socioterritoriais } \\
\text { camponeses no centro do debate }\end{array}$ & Movimentos sociais como questáo secundária \\
\hline Formação de camponeses-militantes & Formação de agricultores-empreendedores \\
\hline Emancipação humana na superação & $\begin{array}{l}\text { Emancipaçáo humana na prosperidade/ } \\
\text { empreendedorismo }\end{array}$ \\
\hline $\begin{array}{l}\text { Criação do conceito de Educaçáo } \\
\text { do Campo pelos movimentos camponeses }\end{array}$ & $\begin{array}{l}\text { Apropriaçáo do conceito } \\
\text { pelos institutos/ONGs }\end{array}$ \\
\hline Campo em conflito/disputas & Campo em harmonia \\
\hline A superação pela revolução como utopia & $\begin{array}{l}\text { A manutenção pelo } \\
\text { empreendedorismo como utopia }\end{array}$ \\
\hline Pedagogia Libertadora & $\begin{array}{l}\text { Pedagogias empreendedora, } \\
\text { de competências e corporativa }\end{array}$ \\
\hline Território construído na disputa & Território construído no diálogo passivo \\
\hline Formação de territórios não capitalistas & Formação de territórios competitivos \\
\hline Educação para cooperação e solidariedade & Educação para competir no mercado \\
\hline Lógica camponesa terra-família-trabalho & Microempresa familiar rural \\
\hline Agronegócio como inimigo & Agronegócio como complemento \\
\hline Campesinato como modo de vida & Agricultor como profissão \\
\hline Camponês como classe antagônica ao capital & $\begin{array}{l}\text { Agricultor como categoria } \\
\text { profissional do capitalismo }\end{array}$ \\
\hline $\begin{array}{l}\text { Desenvolvimento territorial } \\
\text { no conflito com o mercado }\end{array}$ & $\begin{array}{l}\text { Desenvolvimento territorial na ausência do } \\
\text { conflito e na integraçáo ao mercado }\end{array}$ \\
\hline Superação da subalternidade & Naturalização da subalternidade \\
\hline Campesinato na contradiçáo do capitalismo & Campesinato anacrônico ao capitalismo \\
\hline
\end{tabular}

PQA: Paradigma da Questão Agrária; PCA: Paradigma do

Capitalismo Agrário; ONGs: organizaçôes não governamentais. 
está relacionada com a história da estrutura agrária do país, baseada no latifúndio e na desterritorialização (expropriação) das populaçôes camponesas de sua terra de trabalho (CAMACHO et al., 2015). Essa situação de miséria, desigualdade social e avanço destrutivo do capital no campo se complementa com a ausência de políticas públicas de educação. Assim, a busca pela Educação do Campo se torna possível pelo fato de os movimentos socioterritoriais camponeses estarem construindo sua luta pela terra e por um projeto de desenvolvimento para a sociedade diferente do projeto do agronegócio (CALDART, 2005; CAMACHO, 2014).

Dessa forma, a luta pela Educação do Campo tem origem nos problemas socioeconômicos e educacionais enfrentados pelos camponeses e, consequentemente, na busca de soluçôes por parte dos movimentos socioterritoriais camponeses. A necessidade de frear o capitalismo e sua destruiçáo no campo é outra marca do processo. É nesse contexto de contradiçóes — e de lutas para a superação dessas contradiçóes - que a educação surge como um elemento de resistência para auxiliar na luta pela/na terra, a fim de possibilitar a reprodução do campesinato enquanto um modo de vida e uma classe social (CAMACHO, 2014).

A partir dessas características, que são inerentes à gênese e à consolidação da Educação do Campo, é possível entender a existência da relação intrínseca entre a vertente campesinista do PQA e o POEC. Tal interpretação paradigmática sobre o campo permitiu a construção teórico-político-ideológica de uma Educação do Campo libertadora ${ }^{4}$, tendo como elementos centrais o debate da recriação e a resistência camponesa. Essa concepção, ao entender o desenvolvimento do capitalismo no campo como produto do seu processo desigual e contraditório, permite pensar a possibilidade de reprodução do campesinato. Obviamente, essa é condiçẫo primordial para podermos construir a Educação do Campo: sem camponeses não há Educação do Campo.

Outra característica fundamental dessa tendência é a afirmação da permanência camponesa no campo por meio da luta e da resistência contra o capital. Pelo contrário, se pensarmos o campesinato como classe em vias de extinçáo, não será possível de entender a necessidade de construção da educação adequada às especificidades do campesinato. Não faz sentido pensar a construçáo da educação para o modo de vida e a classe social que estaria condenada ao desaparecimento, mesmo que não seja o desaparecimento físico, mas de sua condição social.

Partindo do princípio de que o campo está em disputa entre dois modelos de desenvolvimento territorial antagônicos - agricultura capitalista (latifúndio-agronegócio) e agricultura camponesa —, as propostas condizentes com a educação camponesa não podem vincular-se ao projeto de integração/subordinação capitalista, e sim de defesa dos interesses das classes subalternas (MENEZES NETO, 2009). A Educaçáo do Campo deve ser entendida na contradiçáo da luta de classes, como estratégia de luta dos movimentos sociais, visando à emancipação, como formação humana, conflituosa, porque o campo está em conflito (MICHELLOTI et al., 2010). 
Dessa forma, se faz necessário reafirmarmos a essência da gênese do Movimento de Educação do Campo neste momento histórico de disputa por dois projetos distintos de sociedade. A essência da concepçáo dessa educaçáo foi gerada na prática de luta dos movimentos socioterritoriais camponeses, na luta pela reforma agrária, na luta contra o latifúndio, e pela superação das contradiçóes da lógica do capital. A conflitualidade inerente à lógica de reprodução do capitalismo no campo, desembocando na disputa por territórios materiais-imateriais, entre o agronegócio e os movimentos socioterritoriais camponeses, é um dos elementos centrais que fundamentam a produçáo de nossa análise teórica a respeito da Educação do Campo e seu contexto. A contradição de classe, movimento da história, resulta na produção de paradigmas educacionais a partir de diferentes perspectivas. Dessa maneira, temos que delimitar claramente o território teórico, na perspectiva revolucionária, fazendo-se necessário que a produção do conhecimento esteja ligada à luta de classes, assim como na perspectiva do PQA (SÁ; MOLINA, 2010; CAMACHO, 2014).

Para Molina (2012) e Caldart (2010), alguns órgãos públicos difundem um modelo de Educação do Campo, muitas vezes, afastado dos movimentos sociais e de suas bandeiras de luta e tendem, ideologicamente, a excluir a questão do conflito agrário, pois o enxergam como negativo, devendo ser eliminado. É como se pudéssemos pensar a Educação do Campo sem o campo, sem as contradiçóes, os conflitos, as disputas territoriais, a violência, a expropriação, a resistência e, principalmente, sem os movimentos socioterritoriais camponeses, precursores da Educação do Campo. Essas açóes não dizem respeito ao POEC. Não se pode retirar da Educação do Campo o objetivo de construção de outro projeto de sociedade, nem é possível edificá-la sem inserir a práxis dos sujeitos, as suas necessidades materiais e simbólicas de reprodução.

$\mathrm{Na}$ Educação do Campo, construída a partir do PQA, "ao contrário daquela perspectiva negativa dos conflitos, é preciso reconhecer sua dimensão instituinte: os conflitos devem ser trabalhados politicamente, pois são eles a possibilidade de construção de superaçôes, de mudanças, de transformaçôes" (MOLINA, 2012, p. 592, grifo nosso). Além da conflitualidade, como característica inerente à Educaçáo do Campo, entendemos que se a mesma estiver desvinculada das lutas dos movimentos socioterritoriais, não será considerada verdadeira. Os camponeses são sujeitos históricos ativos do seu processo de reprodução; isto é, não estão, apenas, subdimensionados/passivos à lógica estrutural destruidora do modo de produção capitalista, principalmente, sob a forma moderna e bárbara do agronegócio. Logo, a Educação do Campo, construída juntamente com os movimentos socioterritoriais, passa a ser produto e instrumento de luta, pela/na terra, do campesinato contra a territorialização do capital no campo (CAMACHO, 2014).

Dessa maneira, o Movimento da Educação do Campo tem a intencionalidade de afirmar a identidade territorial dos povos do campo na perspectiva classista da classe territorial camponesa - cuja afirmação se dá na contraposição ao capital agronegócio —, condenando sua lógica exploratória, excludente e hegemônica que 
expropria ou subalterniza o campesinato. Tal perspectiva explicita a conflitualidade inerente ao capitalismo e legitima a luta dos sujeitos oprimidos pela conquista de seus direitos: terra, educação, reconhecimento cultural, étnico etc. (BATISTA, 2007).

Segundo Leher (2007), a educação vinculada aos movimentos sociais engendrou um espaço diferenciado na "batalha das ideias", na produção de conhecimento contrapondo-se ao neoliberalismo. Por isso, é indispensável o estabelecimento de diálogos entre a educação e os movimentos sociais, incitando nova práxis e estabelecendo nova epistemologia. A nova práxis advinda desse diálogo entre os movimentos sociais e a universidade deve colaborar para a ruptura com cinco elementos presentes na realidade: a colonialidade, o capitalismo, a supressáo do público, o eurocentrismo e a perda de autonomia dos movimentos sociais.

Caldart (2010) elabora uma síntese para pensarmos quais são as características centrais dessa Educação do Campo que defendemos. Ela aponta cinco elementos centrais. Primeiro, é a relação entre a particularidade e a universalidade - a educação é particular, mas busca a inserção na universalidade como novo projeto de sociedade. Segundo, ela nasce da experiência de classe dos movimentos camponeses, mas inclui na luta outras classes subalternas. Terceiro, a Educação do Campo mescla a radicalidade pedagógica dos movimentos socioterritoriais camponeses com a luta por políticas públicas. Quarto, ela é um projeto pedagógico da educação formal escolar e, concomitantemente, da educação não formal. E quinto, ela é a luta pelo acesso das classes subalternas ao conhecimento produzido pela humanidade e, ao mesmo tempo, critica o paradigma de produção de conhecimento científico eurocêntrico-colonialista dominante que desconsidera o conhecimento popular produzido pelos sujeitos do campo na lógica não capitalista.

Essa síntese esclarecedora, concernente aos pressupostos principais da Educação do Campo, fortalece nosso objetivo de defender o POEC.

\section{O Programa de Empreendedorismo do Jovem Rural}

Fizemos uma análise crítica da experiência PJER, construída a partir do PCA, no Centro-Sul do Paraná, com sede no município de Guamiranga. O objetivo desse programa é integrar, segura e plenamente, os jovens do campo no processo produtivo, formando empreendedores rurais na lógica da profissionalização dos agricultores e apostando em sua metamorfose em agricultor familiar para competir e se integrar ao mercado: o denominado "agronegocinho". O discurso principal é o de que o fortalecimento da capacidade empreendedora da juventude da agricultura familiar é algo capaz de promover o desenvolvimento territorial sustentável (CAMACHO, 2014).

O PJER recebe apoio técnico, pedagógico e financeiro do ISC e é executado pelo CEDEJOR. Conversamos com representantes do ISC que nos disseram se tratar de uma organização não governamental/organização da sociedade civil de inte- 
resse público (ONG/OSCIP) reconhecida pelo Ministério da Justiça e que, por isso, é independente da companhia Souza Cruz, tendo seu próprio Cadastro Nacional da Pessoa Jurídica (CNPJ). Os programas desenvolvidos pelo instituto visam a atender a sociedade de maneira geral e não aos interesses de produção da empresa. Assim, o alvo não são apenas os produtores ligados à cadeia produtiva da empresa; diferentemente do setor de "responsabilidade social corporativa", que é administrado pela própria companhia, no caso do ISC, trata-se de um investimento social privado. O ISC foi criado em 31 de julho de 2000, a partir da consideração de que havia uma necessidade de construir um projeto que pudesse contribuir com o que é denominado "responsabilidade social das empresas", nas áreas de atuação da empresa Souza Cruz.

É importante entender o que são essas ONGs financiadas pelas empresas do agronegócio ${ }^{6}$. Fontes (2010) explica que, no final da década de 1980, as entidades autonomeadas ONGs tiveram grande impacto no Brasil. Integravam um processo complexo de conversão mercantil-filantrópica da militância. A denominaçáa ONG é confusa em razão do esquecimento do fato de que a contraposição primordial entre governo/público é o privado/empresa, sugerindo uma existência idealizada, apartada tanto da propriedade privada (mercados) quanto da política. A noção de democracia dessas entidades também é idealizada, como sendo uma sociedade civil filantrópica, para a qual todos colaborariam sem conflitos de classes sociais.

Podemos entender as ONGs a partir da categorização gramsciana de aparelhos privados de hegemonia, e partir de seu papel de conservaçáo ou de transformação que deriva de sua atuação orgânica com as classes sociais em luta. Esses aparelhos são extensos e multiformes; deles participam as ONGs, termo confuso e vago, que oculta o debate da luta de classes. As ONGs que expressam a tentativa da unificação de lutas anticapitalistas no cenário mundial são a grande minoria. Temos uma diversidade de formas de sustentaçâoo dessas entidades e algumas, como o ISC, estão ligadas aos setores diretamente empresariais internacionalizados. Nesse caso, é colocada em dúvida a questão da autonomia, que depende, também, de sua capacidade de autofinanciar-se, isto é, de ser capaz de prover a existência de suas próprias organizaçôes, desvinculando-se da lógica dominante e de subordinaçâo ao capital.

A partir da Figura 1 podemos ver o slogan de um evento promovido pelo ISC: "A Jornada Nacional do Jovem Rural". O slogan do evento demonstra claramente a posição assumida no instituto pelo PCA: Por uma Agricultura Familiar, Profissional e Inovadora. Demarcando o território da metamorfose da agricultura familiar que tem como marcas a profissionalização e a inovação.

Segundo um representante do instituto, quem monta o PEJR é o ISC. A ele cabe, também, a formação dos professores e a assistência financeira. A organização dos espaços e a contrataçáo dos professores cabem às organizaçóes parceiras, entre elas o CEDEJOR no sul do Brasil.

O CEDEJOR é uma ONG que realiza atividades de formação com jovens rurais com o objetivo de evitar o êxodo dessa juventude. 
O Centro de Desenvolvimento do Jovem Rural (Cedejor) é uma Organização Civil de Interesse Público (OSCIP), sem fins econômicos e sem finalidade lucrativa, de caráter beneficente, assistencial, educacional, social. Realiza atividades de formaçáo de jovens rurais de 17 a 29 anos. Tem como estratégia a formação integral de jovens residentes no espaço rural visando a ampliaçáo da atratividade destes espaços, para evitar ou minimizar a evasão desses jovens (PEJR, 2010).

O CEDEJOR tem sua sede no Rio Grande do Sul e hoje implementa o PEJR em quatro territórios: Vale do Rio Pardo (RS); Encostas da Serra Geral (SC); Centro-Sul do Paraná (PR); e Caminhos do Tibagi (PR). Essas organizaçóes parceiras que executam o programa, como o CEDEJOR, recebem apoio técnico, pedagógico e financeiro do ISC (INSTITUTO SOUZA CRUZ, 2010). Com relação à localização do CEDEJOR Centro-Sul, sua sede fica no município de Guamiranga (Figuras 2 e 3 ).

Dessa forma, o CEDEJOR é uma ONG que estabelece parcerias públicas, privadas e com o terceiro setor. Como a maioria das ONGs, não tem um horizonte de luta de classes em sua ideologia. Sua concepçáo de campo e de agricultura está embasada no PCA, assim como sua ONG parceira, o ISC. Nas entrevistas que fizemos, notamos que sua intenção é se tornar uma ONG autônoma com relação ao ISC. Todavia, continuará estabelecendo parcerias públicas e privadas. Sua atuação se dá justamente onde os movimentos socioterritoriais camponeses não têm um poder de atuação muito abrangente. Ela se torna, então, a alternativa camponesa na região. Esse fato faz com que a ideologia do agronegócio presente no PCA se expanda entre os territórios camponeses a fim de legitimar a subalternidade desses sujeitos ao capital.

O PEJR (2010) é um documento que apresenta a Unidade Política e o Projeto Pedagógico do Programa de Empreendedorismo do Jovem Rural (PEJR), fundamentando as "concepções orientadoras do programa". Fundamenta e estrutura, teórica e conceitualmente, o processo de formação. Segundo esse documento, o PEJR

\section{Figura 1}

Slogan de evento promovido pelo Instituto Souza Cruz.

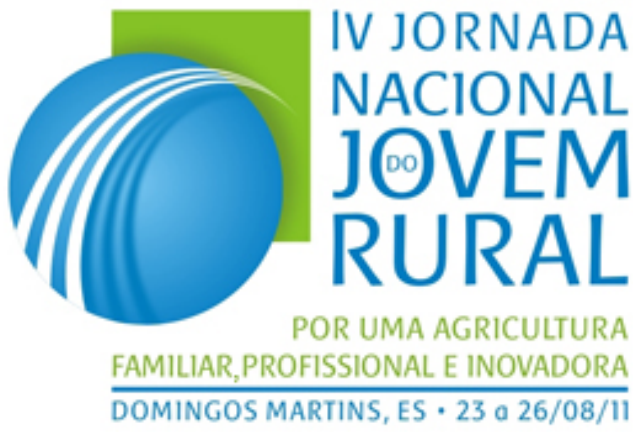


é um programa de formação educacional direcionado a jovens rurais que estão na faixa etária de 16 a 29 anos, que tenham concluído o ensino médio (modalidade de pósmédio) e que residam nos municípios que compóem o território de atuação do centro de formação - no caso de nossa pesquisa, o CEDEJOR do Centro-Sul do Paraná.

O PEJR objetiva formar para o desenvolvimento territorial rural sustentável. $\mathrm{O}$ eixo articulador do processo de aprendizagem é o empreendedorismo do jovem rural. A partir desse eixo são estruturadas as temáticas da agricultura familiar, da juventude rural e do desenvolvimento territorial rural sustentável e solidário. A partir dessas temáticas centrais, o objetivo do curso é capacitar jovens rurais com conhecimentos e habilidades que os permitam aproveitar as oportunidades oferecidas pelo território e pelas politicas públicas para empreender novas oportunidades (PEJR, 2010).

Para alcançar tais objetivos, tendo como referência os pedagogos André e Costa (2004) e Costa (2008), o programa busca desenvolver nos jovens rurais quatro competências. A primeira é a competência pessoal — o jovem aprende a ser jovem no novo contexto rural brasileiro, redefinindo suas iniciativas a partir de sua unidade familiar e das oportunidades do território, buscando as alternativas que lhes são mais atraentes. A segunda é a competência relacional — há uma reflexão sobre como conviver consigo mesmo, com a família, com os atores no território e com a natureza, ou seja, é a compreensão de como estabelecer relações entre pessoas, instituições e meio ambiente. A terceira é a competência produtiva — aprende-se a lidar diretamente com os setores econômicos de produção e distribuiçẫo, como empreendedores.

\section{Figura 2}

Localização do Território Centro-Sul do Paraná.

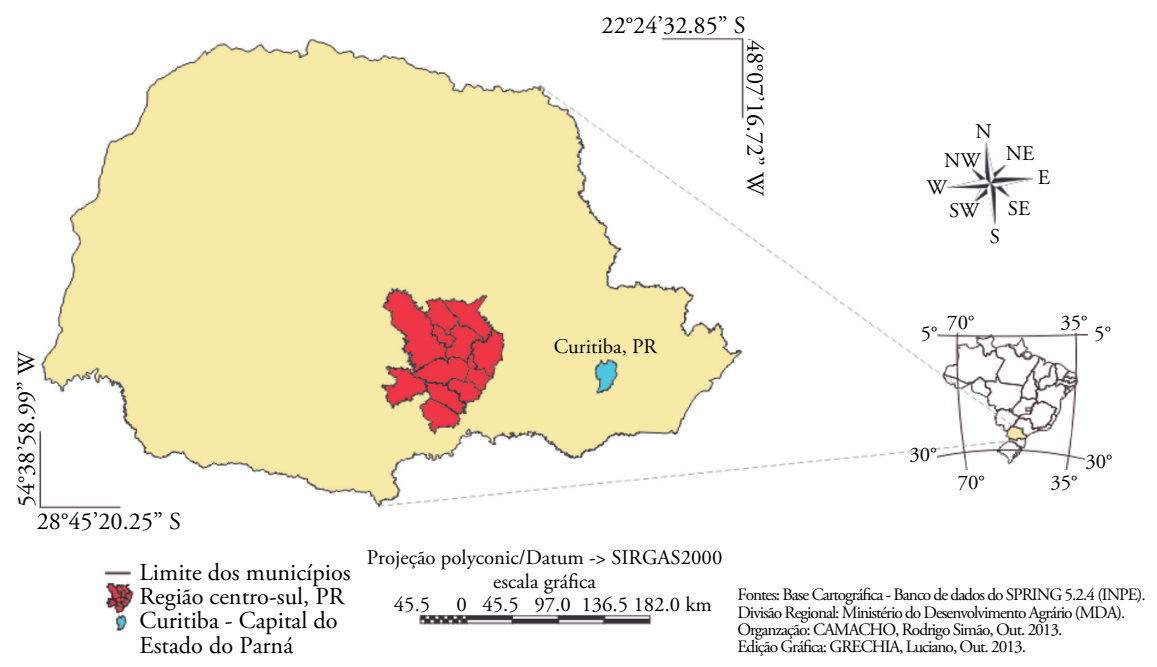

Fonte: Instituto Souza Cruz (2011). 
A quarta é a competência cognitiva - o jovem apreende o conhecimento técnico instituído no novo contexto do rural brasileiro (PEJR, 2010).

Fazendo uma análise crítica a respeito das proposiçóes apresentadas, essa metodologia de ensino-aprendizagem é a denominada pedagogia das competências (RAMOS, 2012). Seu formato se deve ao fato de que, no sistema capitalista, é necessária a construção de um modelo educativo que se justifique, pragmaticamente, por meio de resultados que levem à produtividade e à competitividade, valores a serem alcançados numa educação cuja ideologia atende às classes dominantes. Essa pedagogia é uma proposição ideológica para a formação de sujeitos subalternos ao capital, cujo objetivo é ir moldando o comportamento das classes sociais de acordo com as necessidades do capital em sua fase da acumulação flexível. A conflitualidade e a luta de classes são substituídas pelas competências que os indivíduos podem desenvolver por meio de técnicas a serem apreendidas por uma metodologia de ensino-aprendizagem que garanta o seu desenvolvimento, o adapte às transformaçóes atuais e o inclua de maneira subalterna no modo de produção capitalista (RAMOS, 2012). Adaptação e subalternidade - esse é o verdadeiro sentido da Educação do Campo Empreendedora do PCA, constituída pela pedagogia das competências.

$\mathrm{O}$ enfoque do processo educativo do PEJR é atribuído à ressignificação do ensino do campo com objetivo de atingir a profissionalização dos jovens rurais. Dessa forma, por meio de todos esses elementos centrais destacados, o PEJR se

\section{Figura 3}

Localização da sede do Centro de

Desenvolvimento do Iovem Rural Centro-Sul do Paraná.

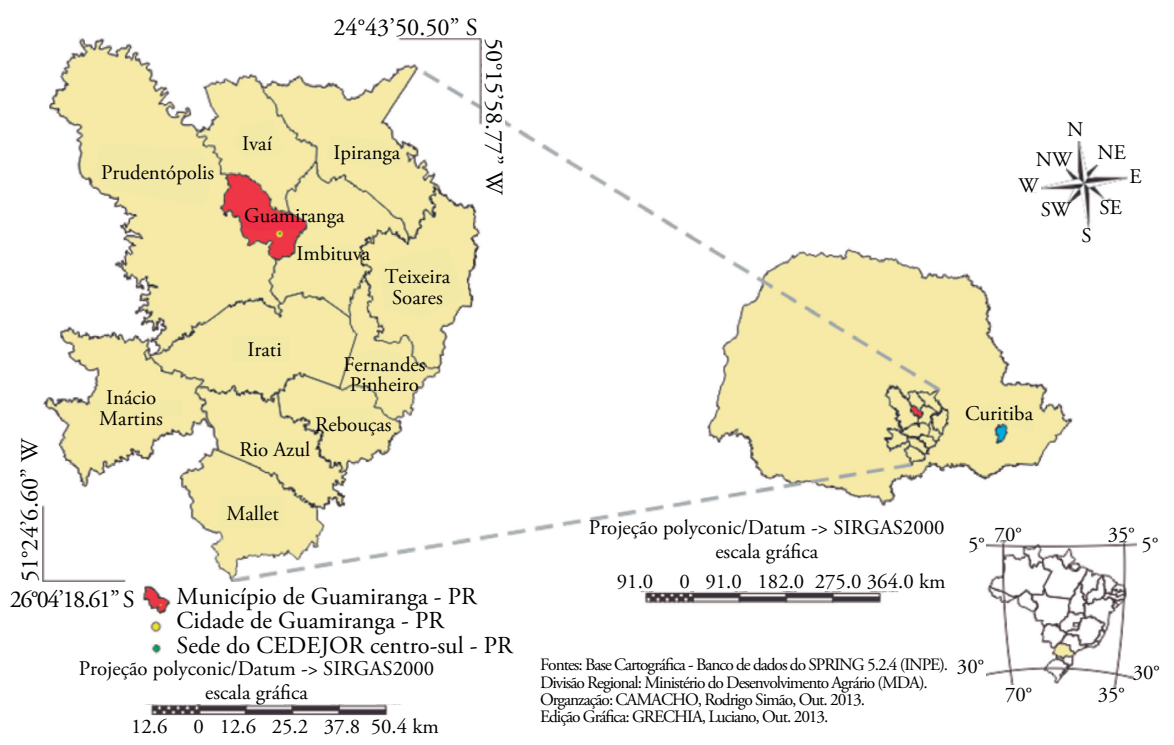


propõe a fazer uma ressignificação da Educação do Campo; por isso, a denominação dada a essa proposta é de ensino do campo. Tal ensino se destina a ser uma formação educacional cujo objetivo é oferecer uma alternativa de formação no contexto das novas profissóes rurais ${ }^{8}$.

\begin{abstract}
Re-significar o Ensino do Campo pelo PEJR implica preparação dos jovens rurais para o exercício das "novas profissóes rurais". Trata-se da formação para oportunidades profissionais com que contam os jovens no contexto atual do rural brasileiro, no qual a pluriatividade e as ocupaçôes rurais não-agricolas ganham relevância, como também as oportunidades proporcionadas pelas políticas e programas públicos. [...] busca formá-la para aproveitar as oportunidades do território, preparando o jovem rural para o processo sucessório na agricultura familiar (PEJR, 2010, p. 7, grifo nosso).
\end{abstract}

Esta ressignificação da Educação do Campo requer a proposição de novas concepções a respeito da juventude rural e da agricultura familiar. Em outras palavras, é necessário construir uma Educação do Campo a partir de outro paradigma que contemple essa visão de mundo a respeito do rural no contexto atual.

\begin{abstract}
A re-significação do ensino por um Programa educacional - e não por uma Escola - pressupóe a assimilação das novas proposiçóes sobre a educação do campo, sobre a juventude rural e sobre as competências que emergem do contexto atual em que a agricultura familiar está inserida (PEJR, 2010, p. 7, grifo nosso).
\end{abstract}

Nessa ressignificação, os movimentos sociais não são os protagonistas do processo, e sim as ONGs que recebem financiamentos do agronegócio. Por isso, o debate sobre os movimentos sociais não faz parte do currículo do programa. Muitos educandos do PEJR não sabem nem o que dizer dos movimentos, outros são a favor, mas observamos muitos educandos-camponeses contrários a eles. Vamos ver qual é a posição de alguns educandos sobre os movimentos sociais em suas narrativas ${ }^{9}$. Dos educandos-camponeses do CEDEJOR, a maioria é contra o MST ou desconhece os objetivos do movimento - como podemos observar nas respostas obtidas a partir de uma entrevista que fizemos na sede do CEDEJOR Centro-Sul, em novembro de 2011.

O educando A diz que: "eles reivindicam os direitos deles, mas de uma forma errada, porque eles invade tudo. Tem uns que invade o terreno das outras pessoa, né". A educanda B afirma: "Ah, eles lutam... pelo que eles querem, só que eu acho que eles não tão muito certo, às vezes, ah... porque [...] eles sempre vão em terras que não é deles [...]". O educando C assevera: "Ah, sei lá, né, cada um pensa diferente, né. Que nem, o Movimento Sem Terra, não é certo o pessoal invadir o terreno dos outro, né [...]. Não sou muito a favor não". A educanda D diz: "Eu não 
concordo muito com isso, né, mas vai de cada pessoa, sei lá. Porque é uma forma, eu acho que, talvez, meio desorganizada de procurarem alguma coisa [...]”.

No mesmo ano, também fizemos uma entrevista com a coordenação pedagógica do PEJR desse CEDEJOR. Dentre nossos questionamentos, perguntamos: "Qual é a sua opiniáo sobre o Agronegócio?” A resposta foi a seguinte:

[...] nós não podemos ser críticos ao agronegócio, ele tem outra função. [...] A agricultura familiar é a que a gente consome com qualidade, né, com qualidade de vida... a família trabalhando dignamente de maneira ecologicamente correta, produzindo o que nós comemos, com qualidade. Só que a gente tem que entender que cada um tem o seu espaço. Não sou contra de maneira alguma ao agronegócio, porque isso também traz um desenvolvimento... faz com que o Brasil seja ai top de linha em alguns aspectos, né. [...].

O debate a respeito da ressignificação da Educação do Campo demarca a importância da compreensão das disputas dos territórios imateriais. Fica claro que cada paradigma dá um conteúdo e uma intencionalidade distinta para o mesmo conceito de Educação do Campo a partir da perspectiva político-ideológica que defendem. Cada experiência construiu seu território imaterial da Educação do Campo. Na Educação do Campo no PCA, perde-se a característica inerente do POEC, que é o vínculo com os movimentos socioterritoriais camponeses, a crítica ao agronegócio e a perspectiva emancipatória. Esse debate passa a ser uma questão secundária diante da importância da integração ao mercado. Essa forma secundária, pelo qual são tratados os temas, leva à formulação de opinióes preconceituosas entre os próprios educandos-camponeses no que concerne aos movimentos camponeses, seguindo os pressupostos da ideologia dominante de criminalização dos movimentos socioterritoriais e de apoio ao agronegócio enquanto modelo de desenvolvimento necessário ao Brasil.

Ao justificarmos de maneira teórica, política e ideológica a existência da Educação do Campo em dois paradigmas, partimos da premissa de que esse modelo de educação está em disputa, porque o campo está em disputa por modelos distintos de desenvolvimento territorial e educacional. A Educação do Campo nasceu da luta dos movimentos camponeses, mas foi apropriada pelas grandes empresas e seus institutos de responsabilidade social (caso do ISC). Muitas das práticas intituladas de Educação do Campo são reacionárias e romperam com o caráter revolucionário, essência da sua origem. Essas experiências têm reforçado a alienação no que concerne aos interesses de classe. Se a sociedade é formada por classes antagônicas, os territórios materiais-imateriais estão em conflito por modelos antagônicos de desenvolvimento rural. No interior dessa disputa, encontra-se a Educação do Campo (SÁ; MOLINA, 2010; CAMACHO, 2014). 


\section{Considerações finais}

Os projetos distintos de Educação do Campo nos mostram os territórios imateriais em disputa pelas classes sociais que compóem a sociedade capitalista. A Educação do Campo no PQA origina-se dos próprios camponeses. Por outro lado, grandes empresas ligadas ao agronegócio e seus institutos de responsabilidade social, desvinculados das lutas camponesas e amparados sob os pressupostos do PCA, se apropriaram da Educação do Campo, ressignificando seu conteúdo e objetivos. De emancipatória, passou a servir como legitimadora da subordinação dos camponeses ao capital. Isso porque as experiências de educação de cunho neoliberal ficam dentro de um limite estipulado para que não atrapalhem os objetivos de reprodução da classe dos capitalistas-latifundiários do campo. Assim, na perspectiva da Educação do Campo no PQA, ao contrário da integração, devemos instrumentalizar os sujeitos com conhecimentos que permitam fazer a luta contra o capital. Logo, a visão de campo dos paradigmas direciona os objetivos da Educação do Campo, constituindo-se na dicotomia "integração no PCA e superação no PQA".

Não tem como uma proposta de Educação do Campo, camponesa em sua essência, ser pensada a partir do agronegócio. O que significa que essa Educação está servindo para duas finalidades: para formação de mão de obra qualificada para o agronegócio ou para disseminar a ideologia do PCA entre os estudantescamponeses. Ideologia que defende a ruptura com a luta de classes e a subalternidade da agricultura familiar ao agronegócio. Essa é a saída possível que a modernização agrícola capitalista reservou aos camponeses para continuarem a existir.

Perde-se o sentido de emancipação/superação/ruptura; e ele é substituído pela adaptação/subordinação/continuidade. Como mencionava Freire (1983; 1999), as elites utilizam-se da educação para difundir a sua ideologia e manter a dominação, a opressão e a desigualdade inerente ao modo de produção vigente. É, ideologicamente, negada a existência de um campo em conflito e disputas territoriais entre camponeses, indígenas e quilombolas contra o agronegócio.

A Educação do Campo deve ser a oposição ao modo de vida imposto pela sociabilidade-territorialidade do capital (MOLINA, 2012). Pelo fato de ser uma Educação Territorial (FERNANDES, 2008), significa que está diretamente relacionada com a perspectiva de criação de territórios a partir de uma "lógica camponesa", na qual os camponeses são sujeitos da produção de seus territórios/territorialidades - espaços que têm como marca suas vontades, capacidades, emoçóes, necessidades etc. A partir dessas premissas podemos considerar que, enquanto a Educação do Campo no PQA busca resistir à invasão da territorialidade do capital nos territórios camponeses, a Educação do Campo no PCA busca a adaptaçáo do camponês à territorialidade do capital. 


\section{Notas}

1. Kuhn definiu o conceito de paradigma como "as realizaçôes cientificas universalmente reconhecidas que, durante algum tempo, fornecem problemas e soluçöes modelares para uma comunidade de praticantes de uma ciência" (KUHN, 1994, p. 13, grifo nosso).

2. "A primeira formulação do conceito de agronegócio (agribusiness) é de Davis e Goldberg, 1957. Para os autores, o agronegócio é um complexo de sistemas que compreende agricultura, indústria, mercado e finanças" (FERNANDES, 2008, p. 165).

3. Movimentos socioterritoriais é um conceito criado para explicar a produção/construção/transformação dos territórios gerada pelos movimentos sociais. Alguns movimentos sociais são formados por sujeitos que lutam pela conquista de seus territórios, como os movimentos camponeses, indígenas e quilombolas (FERNANDES, 2005).

4. Pensando a partir da Pedagogia de Freire (1983; 1999).

5. Alegando "responsabilidade social", muitas vezes, com financiamento público direto ou indireto (quando obtém isenção fiscal como contrapartida), o capital estende suas ações "pedagógicas" e alcança um triplo objetivo: controlar a formação de trabalhadores, elevar seu capital de marca (a valorização de sua imagem na sociedade majora o valor das açóes no mercado financeiro e constitui exigência dos investidores para adquirir tais papéis) e obter vantagem na disputa de hegemonia, pela difusão de sua visão de mundo para a empresa e além de seus muros (TIRADENTES, 2012, p. 248, grifo nosso).

6. Ressaltamos que náo temos a intençáo de aprofundarmos o debate a respeito da diversidade de ONGs existentes e dos seus diferentes pressupostos teórico-político-ideológicos que influenciam suas açôes. Nosso recorte trata-se dos institutos vinculados ao setor de responsabilidade social das empresas do agronegócio, mais especificamente o ISC.

7. A Rede Jovem Rural é um projeto coletivo com objetivo de promover açóes de cooperação e defesa conjunta da causa do jovem rural brasileiro. Cinco organizaçóes, juntamente com o ISC, formam a rede. São elas: Associaçấo Regional das Casas Familiares Rurais do Sul do Brasil (Arcafar Sul); CEDEJOR; Movimento de Educação Promocional do Estado do Espírito Santo (MEPES); Movimento de Organização Comunitária (MOC); e Serviço de Tecnologia Alternativa (SERTA). Busca-se constituir um espaço para troca de experiências, especialmente em torno dos temas empreendedorismo do jovem e desenvolvimento sustentável em territórios rurais (ISC, 2010).

8. Debate criado pelo PCA a partir de Veiga (2002).

9. A partir de um questionário semiestruturado e observaçáo participante, fizemos uma entrevista gravada com um grupo de 15 educandos-camponeses do PEJR. Nessa entrevista, eles contaram sobre seu modo de vida, o que pretendiam quando vieram fazer o curso e o que mudou após sua entrada. Dentre as questôes que fizemos, destacam-se: Qual é a sua opinião a respeito dos Movimentos Sociais do Campo?; Qual é a sua opinião sobre o Agronegócio?; O que é o Empreendedorismo? 
10. (ALMEIDA; PAULINO, 2010; ARROYO, 2004; BATISTA, 2007; CALDART, 2005, 2010; CAMACHO, 2014; FERNANDES, 2005, 2008, 2009; FONEC, 2012; FREIRE, 1983, 1999; LEHER, 2007; MARQUES, 2008; MARTINS, 1981, 2002; MENEZES NETO, 2009; MOLINA, 2012; OLIVEIRA, 1986, 2004; SHANIN, 2008).

11. (ABRAMOVAY, 1992; ANDRÉ; COSTA, 2004; BURGARDT, 2011; INSTITUTO SOUZA CRUZ, 2010; PEJR, 2010; VEIGA, 2002).

\section{Referências}

ABRAMOVAY, R. Paradigmas do capitalismo agrário em questão. Campinas: Hucitecl Unicamp, 1992.

ALMEIDA, R.A. de; PAULINO, E.T. Terra e território: a questão camponesa no capitalismo. Sáo Paulo: Expressão Popular, 2010.

ANDRÉ, S.; COSTA, A.C.G. da. Educação para o desenvolvimento humano. São Paulo: Saraiva, 2004.

ARROYO, M.G. A educação básica e o movimento social do campo. In: ARROYO, M.G.; CALDART, R.S.; MOLINA, M.C. (Orgs.). Por uma educação do campo. Petrópolis: Vozes, 2004. p. 67-86.

ARROYO, M.G.; CALDART, R.S.; MOLINA, M.C. Apresentação. In: ARROYO, M.G.; CALDART, R.S.; MOLINA, M.C. (Orgs.). Por uma educação do campo. Petrópolis: Vozes, 2004. p. 7-18.

BATISTA, M. do S.X. Movimentos sociais e educação popular do campo (Re) constituindo Território e a Identidade Camponesa. In: JEZINE, E.; ALMEIDA, M. de L.P. de. (Orgs.). Educação e movimentos sociais: novos olhares. Campinas: Alínea, 2007. p. 169-190.

BURGARDT, S.B. Plano de Desenvolvimento Institucional do CEDEJOR - Centro de Desenvolvimento do Jovem Rural. Florianópolis: CEDEJOR, 2011.

CALDART, R.S. Educação do campo: notas para uma análise de percurso. In: MOLINA, M.C. (Org.). Educação do campo e pesquisa II: questóes para reflexão. Brasília: MDA/ MEC, 2010. p. 103-126. (Série NEAD Debate, 20).

Elementos para a construção de um projeto político e pedagógico da educação do campo. In: MOLINA, M. C.; JESUS, S. M. S. A. de. (Org.). Por uma educação do campo: contribuições para a construção de um projeto de educação do campo. Brasília: Articulação Nacional "Por Uma Educação do Campo", 2004, p. 13-53. (Por Uma Educação do Campo, 5).

CAMACHO, R.S. Paradigmas em disputa na educação do campo. 806 p. Tese (Doutorado em Geografia) - Faculdade de Ciências e Tecnologia, Universidade Estadual Paulista "Júlio de Mesquita Filho", Presidente Prudente, 2014.

CAMACHO, R.S.; SOBREIRO FILHO, J.; SOBREIRO, V.A.; MARIANO, E.B. Evaluation of the relationship between education and sustainability in peasant movements: the experience of the national education program in agrarian reform. Evaluation and Program Planning, v. 1, p. 1-23, 2015. 
COSTA, A. C. G. Educação. São Paulo: Editora Canção Nova, 2008

FERNANDES, B.M. Conflitualidade e desenvolvimento territorial. In: BUAINAIN, A.M. Luta pela Terra, Reforma Agrária e Gestão de Conflitos no Brasil. Campinas: Editora Unicamp, 2008.

. Movimentos socioterritoriais e movimentos socioespaciais: contribuição teórica para uma leitura geográfica dos movimentos sociais. Nera, Presidente Prudente, ano 8, n. 6, p. 14-34, jan./jun. 2005.

- Questão agrária: conflitualidade e desenvolvimento territorial. Disponível em: <http://bibspi.planejamento.gov.br/bitstream/handle/iditem/564/Quest\%C3\%A3o\%20 agr $\%$ C $3 \%$ A 1 ria conflitualidade $\% 20 \mathrm{e} \% 20$ desenvolvimento $\% 20$ territorial. pdf?sequence $=1>$. Acesso em: 20 maio 2009.

FÓRUM NACIONAL DE EDUCAÇÃO DO CAMPO (FONEC). Notas para a análise do momento atual da Educação do Campo. Seminário Nacional, ago. 2012.

FONTES, V. O Brasil e o capital imperialismo: teoria e história. 2. ed. Rio de Janeiro: EPSJV; UFRJ, 2010. (Pensamento Crítico, 15).

FREIRE, P. Pedagogia da autonomia: saberes necessários à pratica educativa. 12. ed. São Paulo: Paz e Terra, 1999.

. Pedagogia do oprimido. 13. ed. Rio Janeiro: Paz e Terra, 1983.

INSTITUTO SOUZA CRUZ. Instituto Souza Cruz 10 anos: potencializando os territórios rurais com empreendedorismo, talento e inovação. Jovens em Campo, ano 3, n.17, p. 1-4, mar./abr. 2010.

KAUTSKY, K. A questão agrária. Tradução de C. Iperoig. 3. ed. São Paulo: Proposta Editorial, 1980. (Proposta Universitária).

KUHN, T.S. A estrutura das revoluções científicas. 3.ed. São Paulo: Perspectiva, 1994.

LEHER, R. Educação popular como estratégia política. In: JEZINE, E.; ALMEIDA, M. de L.P. de. (Orgs.). Educaçâo e movimentos sociais: novos olhares. Campinas: Alínea, 2007. p. 19-32.

MARQUES, M.I.M. A atualidade do uso do conceito de camponês, Nera, Presidente Prudente, ano 11, n. 12, p. 57-67, jan./jun. 2008.

MARTINS, J. de S. A sociedade vista do abismo. Petrópolis: Vozes, 2002.

Os camponeses e a politica no Brasil. Petrópolis: Vozes, 1981.

MENEZES NETO, A.J. de. Formação de professores para a educação do campo: projetos sociais em disputa. In: ANTUNES-ROCHA, M.I.; MARTINS, A.A. (Orgs.). Educação do Campo: desafios para a formação de professores. Belo Horizonte: Autêntica, 2009. p. 25-37. (Coleção Caminho da Educação do Campo, 1).

MICHELLOTI, F.; SILVA. J.B.; REIS, N.S.; SOUZA, O.N.B.; HAGE, S.M.; SOUZA, R.P.; MEDEIROS, L.S. Educação do campo e desenvolvimento. In: MOLINA, M.C. (Org.). Educação do campo e pesquisa II: questôes para reflexão. Brasília: MDA/MEC, 2010. p. 13-25. (Série NEAD Debate, 20). 
MOLINA, M.C. Políticas Públicas. In: CALDART, R.S.; PEREIRA, I.B.; ALENTEJANO, P.; FRIGOTTO, G. (Orgs.). Dicionário da Educação do Campo. Rio de Janeiro: Escola Politécnica de Saúde Joaquim Venâncio; São Paulo: Expressão Popular, 2012. p. 587-596.

OLIVEIRA, A.U. de. Geografia agrária: perspectivas no início do século XXI. In: OLIVEIRA, A.U. de; MARQUES, M.I.M. (Orgs.). O campo no século XXI: território de vida, de luta e de construção da justiça social. São Paulo: Casa Amarela; Paz e Terra, 2004.p. 27-64.

Modo capitalista de produção e agricultura. São Paulo: Ática, 1986.

PROGRAMA DE EMPREENDEDORISMO DO JOVEM RURAL (PEJR). Unidade Política e Projeto Pedagógico. Documento de Trabalho (Versão 20 jul. 2010). Viçosa: PEJR; CEDEJOR; Instituto Souza Cruz; UFV, 2010.

RAMOS, M. Pedagogia das competências. In: CALDART, R.S.; PEREIRA, I.B.; ALENTEJANO, P.; FRIGOTTO, G. (Orgs.). Dicionário da Educação do Campo. Rio de Janeiro: Escola Politécnica de Saúde Joaquim Venâncio; São Paulo: Expressão Popular, 2012. p. 535-539.

SÁ, L.M.; MOLINA, M.C. Políticas de educação superior no campo. In: MOLINA, M.C. (Org.). Educação do campo e pesquisa II: questóes para reflexão. Brasília: MDA/ MEC, 2010. p. 74-83. (Série NEAD Debate, 20).

SHANIN, T. Lições camponesas. In: PAULINO, E.T.; FABRINI, J.E. (Orgs.). Campesinato e territórios em disputa. São Paulo: Expressão Popular; UNESP, 2008. p. 23-29. (Geografia em Movimento).

TIRADENTES, A. Educaçáo corporativa. In: CALDART, R.S.; PEREIRA, I.B.; ALENTEJANO, P.; FRIGOTTO, G. (Orgs.). Dicionário da Educação do Campo. Rio de Janeiro: Escola Politécnica de Saúde Joaquim Venâncio; São Paulo: Expressão Popular, 2012. p. 247-252.

VEIGA, J.E. da. A face territorial do desenvolvimento. Interaçôes, v. 3, n. 5, p. 5-19, set. 2002.

Recebido em 30 de março de 2017.

Aceito em 25 de agosto de 2017. 